\title{
Raman Analyses of Residual Stress in Diamond thin Films Grown on Ti6Al4V Alloy
}

\author{
Adriana F. Azevedo ${ }^{\mathrm{a}, \mathrm{b}} *$, Evaldo J. Corat ${ }^{\mathrm{a}}$, Nélia F. Leite ${ }^{\mathrm{a}}$, Neidenei G. Ferreira ${ }^{\mathrm{a}}$, \\ Vladimir J. Trava-Airoldi ${ }^{\text {a }}$ \\ anstituto Nacional de Pesquisas Espaciais - INPE \\ Av. dos Astronautas 1758, C.P. 515, 12201-970 São José dos Campos, SP - Brazil \\ ${ }^{\mathrm{b}}$ Faculdade de Engenharia Química de Lorena - Faenquil/Demar - Lorena, SP - Brazil
}

Received: January 02, 2002; Revised: September 30, 2002

\begin{abstract}
The stress evolution in diamond films grown on Ti6Al4V was investigated in order to develop a comprehensive view of the residual stress formation. Residual stress is composed of intrinsic stress induced during diamond film growth and extrinsic stress caused by the different thermal expansion coefficients between the film and substrate. In the coalescence stage it has been observed that the residual stress is dominated by the microstructure, whereas on continuous films, the thermal stress is more important. In this work diamond thin films with small grain size and good size and good quality were obtained in a surface wave-guide microwave discharge, the Surfatron system, with a negative bias voltage applied between the plasma shell and substrate. For above of $-100 \mathrm{~V}$ applied bias, the ratio of carbon $\mathrm{sp}^{3} / \mathrm{sp}^{2}$ bond may increase and the nucleation rate increase arising the high value at the $-250 \mathrm{~V}$ applied bias. Stress measurements and $\mathrm{sp}^{3}$ content in the film were studied by Raman scattering spectroscopy. The total residual stress is compressive and varied from -1.52 to $-1.48 \mathrm{GPa}$ between 0 and $-200 \mathrm{~V}$ applied bias, respectively, and above the $-200 \mathrm{~V}$, the compressive residual stress increased drastically to $-1.80 \mathrm{GPa}$. The diamond nucleation density was evaluated by top view SEM images.
\end{abstract}

Keywords: diamond nucleation, bias enhanced nucleation (BEN), plasma, stress

\section{Introduction}

Diamond thin films grown by chemical vapor deposition (CVD) have been studied because of their unique properties, such as, high hardness, very low friction coefficient, biocompatibility, etc. They also are very promising for a number of mechanical, biological and chemical applications $^{1-5}$. However, there are still a number of unsolved issues regarding the diamond nucleation and growth processes. First, it is extremely difficult to nucleate and grow diamond on several metallic alloys because the rapid carbon diffusion, for instance, within titanium based materials. This behavior may promote a substantial decrease of carbon concentration on the surface and consequently dropping diamond nucleation and growth. Therefore, the diamond nucleation is considered one of the keys issues in diamond growth due its influence on physical and chemical

*e-mail: adriana@las.inpe.br characteristics ${ }^{6}$.

Over the last years, Yugo et al. ${ }^{7,8}$ have shown that the nucleation density of diamond increased by negatively biasing the substrates in methane-hydrogen plasma, so-called bias enhanced nucleation (BEN). In the presence of applied bias, actived ions in a plasma sheath undergo both internal diffusion into and surface migration on the substrate. Most actived species induce carbide migration through the substrate surface and to form a cluster by mixing with the substrate. The cluster structure formed at the beginning of this process is not completely clear; however, it is considered a hydrogenated $\mathrm{sp}^{2}$ rich amorphous carbon cluster, which can be regarded as a precursor of the diamond nucleus.

The other unsolved issue regarding the diamond deposition, specifically on Ti6Al4V alloys, is a poor film adhesion that occurs in part because of the thermal expansion 
mismatch between diamond and the substrate. As the thermal stress contribution only covers a fraction of the total stress, various sources of stresses, including coherency strains, capillary effects and the effect of grain coalescence are widely discussed based on both experimental evidence and theoretical considerations of their contributions to the overall stress. Michler et al. ${ }^{9}$ showed that the microstructure, in particular coherency strains, surface energy effects, non-diamond material at the grain boundaries, structural defects and disclinations during grain coalescence, can contribute substantially to the observed compressive stress. In order to understand the relationship between the diamond nucleation and the residual stress, several researchers have been working with BEN between the substrate and plasma, before of the diamond growth, in order to increase the nucleation rate ${ }^{10,11}$.

Even though the BEN process and its mechanism have been intensively studied by many researchers, the influence of experimental conditions of BEN and on residual stress have not been fully clarified yet. In this work results describing the influence of bias enhancement voltage on the diamond nucleation on titanium alloys using Surfatron system are presented for the first time. The effect of bias enhanced nucleation at the onset nucleation stage and the improvement of diamond film quality grown using a Surfatron system will also be presented. Finally, the residual stress in diamond nucleation stage will be discussed as function of the different bias voltage.

\section{Experimental Procedure}

Diamond depositions were performed using the Surfatron system, which is composed of the launcher and two coaxial dielectric tubes, as has been described elsewhere $^{12-16}$. The external tube is made of Pyrex and used as a wall jacket for flowing the cooling liquid, the dimetylpolisiloxane (DMPS) that is transparent to the $2.45 \mathrm{GHz}$ microwave wavelength. The inner tube is made of quartz and used as a discharge tube. The surface wave (SW) is launched through a GAP and it propagates on the structure formed by the sustained plasma and the discharge tube. The abrupt transition of the discharge tube is essential to finish the SW propagation and create an expanded hemispherical plasma slightly below the transition as it is depicted in Fig. 1. The uniform plasma shell of approximately a few millimeters thickness has high energy density. The substrate is placed close to this plasma shell, $0.5 \mathrm{~mm}$ approximately. The bias voltage is applied between the substrate and the plasma shell. A schematic diagram of the bias application inside quartz tube of Surfatron system is also shown in Fig. 1. Different cathode positions were studied as a function of plasma shell. The best position is at the end of the coaxial plunger that the electrodes don't influ-

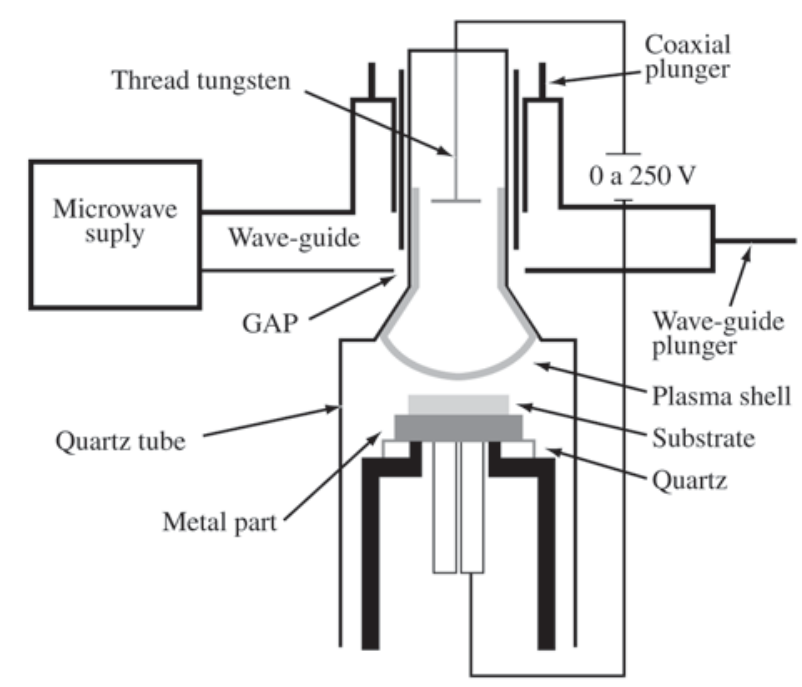

Figure 1. Schematic diagram for BEN inside quartz tube in the Surfatron system.

ence in the plasma stability.

Depositions were carried out on Ti6Al4V $1 \times 1 \mathrm{~cm}^{2}$ and $0.75 \mathrm{~mm}$ thick substrate. The samples were mechanically polished using silicon carbide papers $(600,1000$ grid), followed by chemical polishing using oxalic acid with aluminum oxide pastes $(9 \mu \mathrm{m}, 5 \mu \mathrm{m}, 2 \mu \mathrm{m})$. After, the samples were cleaned and pretreated by ultrasonic hexane bath with $0.25 \mu \mathrm{m}$ diamond powder during $60 \mathrm{~min}$.

The experimental conditions were the deposition temperature on substrate surface, $\mathrm{T}_{\text {dep }}$, around $700{ }^{\circ} \mathrm{C}$, the time of bias application, $\mathrm{t}_{\mathrm{b}}$, was $30 \mathrm{~min}$ and negative bias was varied from 0 to $-250 \mathrm{~V}$. The gas mixture of $2.0 \%$ methane in hydrogen was selected to obtain a high carbon concentration $^{17-19}$. The gas flow was kept constant at $100 \mathrm{sccm}$ and the pressure inside the reactor was 26 torr. The microwave power was set at $2.5 \mathrm{~kW}$ for all experiments.

In order to evaluate the process of grain formation and to determine the nucleation density at different bias voltages, scanning electronic microscopy (SEM) analysis were performed using a LEO 440 microscope system. The diamond content in the films, film quality and the residual stress, as a function of the bias voltage, were evaluated by using micro-Raman scattering spectroscopy. All Raman spectra were fitted with Lorentzian lines to separate the contribution of the pure diamond and the other non-diamond phases.

\section{Results and Discussions}

The difficulty of fast diamond nucleation on Ti6Al4V was overcome with a BEN between the plasma shell and the substrate. Figure 2 shows SEM micrographs evidenc- 
ing the diamond grain density on Ti6Al4V substrate when the negative bias voltage from -50 up to $-250 \mathrm{~V}$ is applied on Ti6Al4V substrate. Diamond growth parameters were
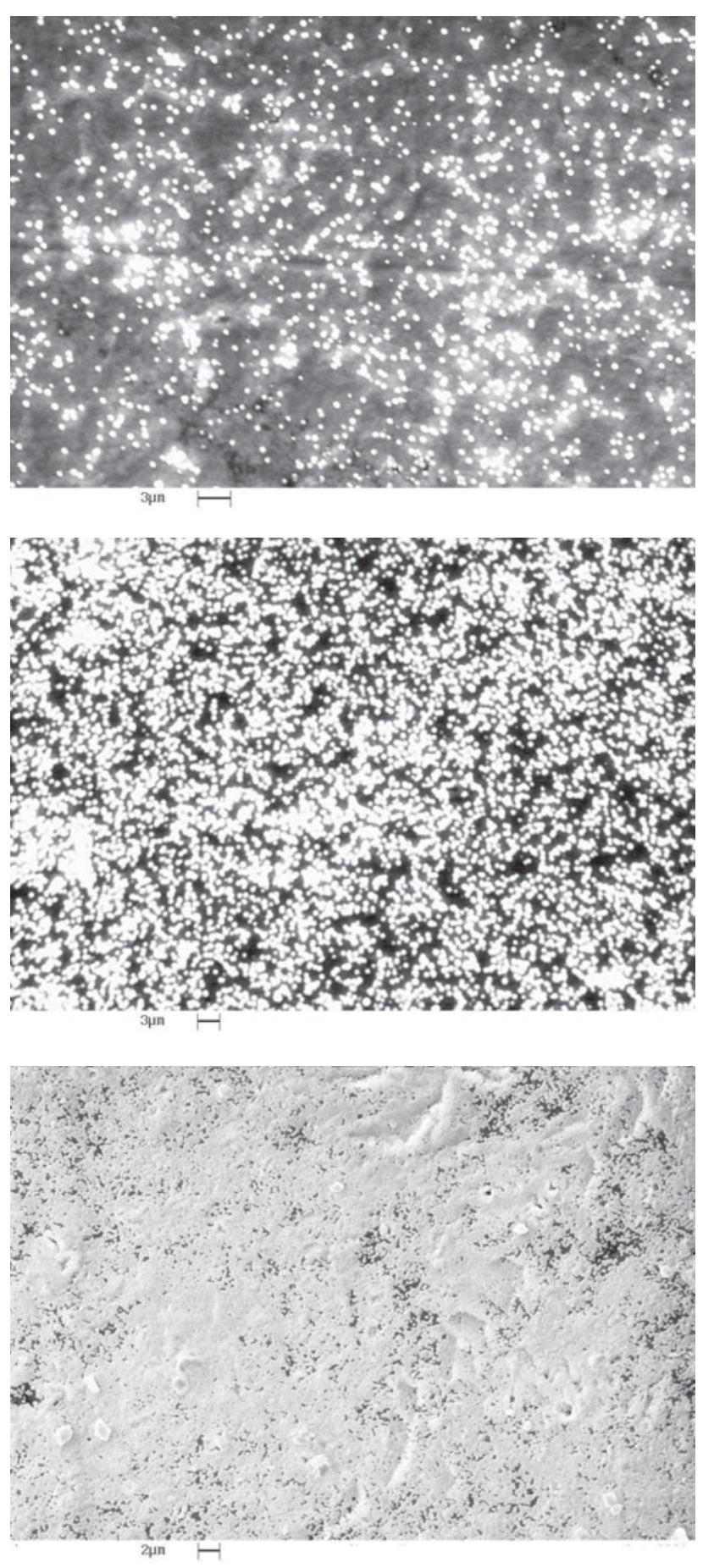

Figure 2. Top view scanning electron micrographs, in the same magnification, for the nucleation on Ti6Al4V substrate using (a) -50; (b) -150; (c) -250 V bias, respectively. fixed as mentioned above. The grains started to appear faster when the bias voltage of $-50 \mathrm{~V}$ was applied, as it is shown in Fig. 2a. At $-150 \mathrm{~V}$ bias condition, grains were deposited uniformly on the substrate, as depicted in Fig. $2 b$ and by increasing the bias voltage, the grains tended to coalescence and grow uniformly, as shown in Fig. 2c. It is apparent that a negative bias voltage of $-250 \mathrm{~V}$ induce an acceleration of the diamond nucleation. After $30 \mathrm{~min}$, the average grain size in all samples is around $200 \mathrm{~nm}$. In addition, from the SEM micrographs, the grain density was evaluated. As it is shown in Fig. 3, the grains density slowly increase until approximately $4.0 \times 10^{8}$ particles.cm ${ }^{-2}$ up to $-200 \mathrm{~V}$ applied bias and rapidly increase for $-250 \mathrm{~V}$ bias voltage, reaching the value of approximately $1.6 \times 10^{9}$ particles. $\mathrm{cm}^{-2}$. This value represents an increase of 18 times in relation to the sample without applied bias. One can speculate that the bias method is based on the compound effects of ions with various energies ${ }^{17}$. In the low bias voltage values, around $-50 \mathrm{~V}$, the ions may exert some chemical effect, such as cleaning of the substrate and surface migration, larger than the physical effects. In the high bias voltage values, around $-200 \mathrm{~V}$, the physical effects, such as subplantation and selective etching, become dominant in relation to the chemical effects improving the nucleation rate.

Therefore, some of the advantages of applied bias voltage were confirmed, such as the increase of nucleation rate and the decrease of grain size. In this context, it is also important to study the diamond film quality, diamond content in the film and the stress evolution even during the nucleation stage and to be able to determine the onset stress contribution.

The film quality was evaluated by Raman scattering spectroscopy. In order to improve the Raman data statistics, a larger number of spectra were recorded from a sample area.

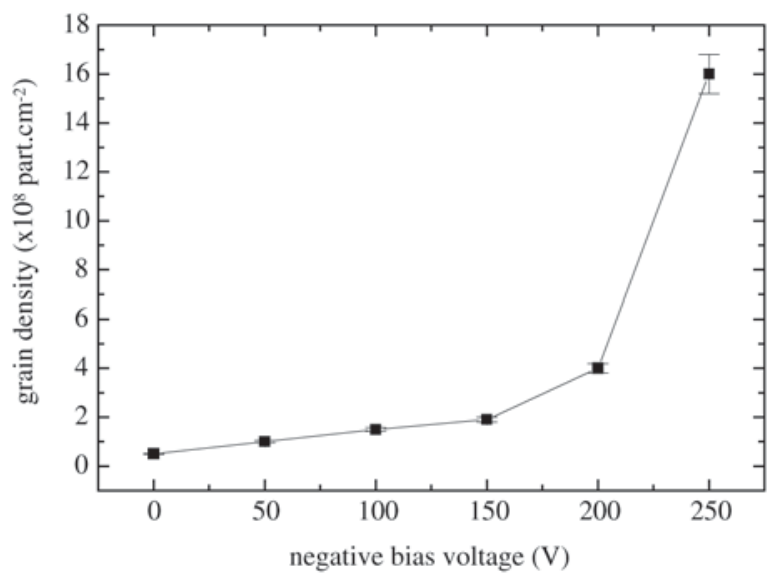

Figure 3. Diamond nucleation density as function of applied bias voltage. 
It were chosen five points in an area of $4.0 \mathrm{~mm}^{2}$ and the spectra were scanned five times on each point of such area.

The Raman spectra of diamond nucleation obtained at $-50,-150$ and $-250 \mathrm{~V}$ bias voltages are shown in Fig. 4. The Raman spectra of all samples exhibited, in addition to the evident diamond peak around $1336 \mathrm{~cm}^{-1}$, a broad band centered around $1560 \mathrm{~cm}^{-1}$, which is attributed to disordered graphitic carbons. Also, Raman scattering spectra show an evolution of a small peak centered at $1134 \mathrm{~cm}^{-1}$ as a function of the applied bias, which corresponds to the nanocrystalline diamond ${ }^{20,21}$. This result suggest us to intensify the fundamental studies in order to get a better understanding about the nano-crystalline structure and to obtain smaller and highly oriented diamond (HOD) grains.

The diamond content in the film, also called diamond purity, can be obtained by a quantitative analysis of the Raman spectrum. To separate the contributions of diamond and disordered graphitic phases, the whole spectra were fitted using Lorentzian lines. To fit the broad band centered at $1550 \mathrm{~cm}^{-1}$, it was necessary to take three different contribution bands: the $\mathrm{D}$ and $\mathrm{G}$ peak of polycrystalline graphite around $1345 \mathrm{~cm}^{-1}$ and $1560 \mathrm{~cm}^{-1}$, respectively and a low intensity band centered approximately at $1470 \mathrm{~cm}^{-1}$ attributed to a tetrahedral bonded diamond precursor. The diamond amount in the films $\left(\mathrm{C}_{\mathrm{d}}\right)$ can be calculated by a relative Raman cross section of diamond to graphite of $1 / 50$ from the relation ${ }^{22,23}$ :

$$
C_{d}=\frac{100 A_{d}}{\left(A_{d}+\frac{\sum A_{i}}{50}\right)}
$$

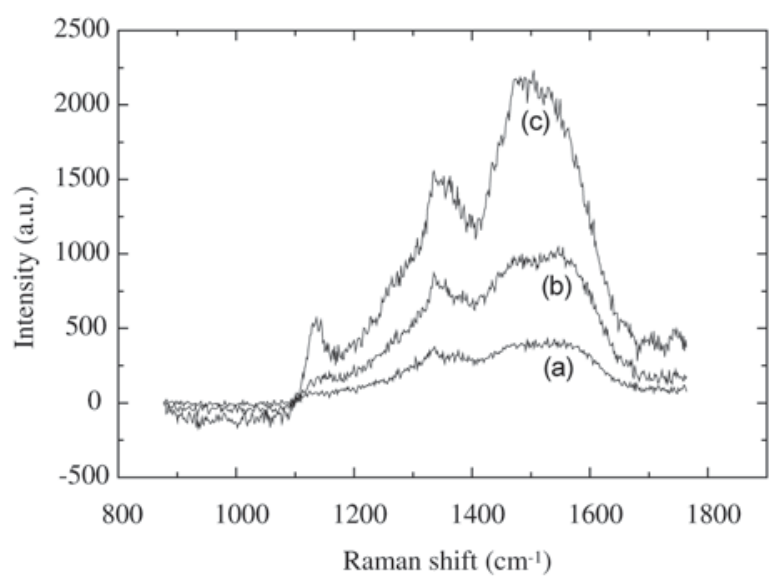

Figure 4. The Raman spectra of diamond coatings at different applied bias voltages: (a) -50 ; (b) -150 ; (c) $-250 \mathrm{~V}$. where $A_{d}$ and $A_{i}$ are the area of the fitted curves corresponding to the $1332 \mathrm{~cm}^{-1}$ diamond peak and the graphitic bands, respectively. This procedure was accomplished for all the samples and in Fig. 5 is shown the diamond content as a function of the applied negative bias. The diamond content increases approximately from $94 \%$ to $98 \%$ between 0 and $100 \mathrm{~V}$ bias and remains at this value for higher bias voltages. We concluded that the carbon ions were accelerated to the substrate by the bias voltage to form $\mathrm{sp}^{2}$ non-crystalline clusters and these clusters were removed and transformed into $\mathrm{sp}^{3}$ clusters through the collision of carbon ions and etching by hydrogen ions. This conclusion is in agreement with the studies mentioned in the paper ${ }^{17}$. Therefore, this transformation may be very slow until $-100 \mathrm{~V}$ applied bias. However, above of $-100 \mathrm{~V}$ applied bias, the ratio of carbon $\mathrm{sp}^{3} / \mathrm{sp}^{2}$ bond may increase and the nucleation rate increase arising the high value at the $-250 \mathrm{~V}$ applied bias.

Other important study that can be investigated from Raman scattering spectra is the total residual stress of the diamond films. The total residual stress is the sum of thermal stress and intrinsic stress. The thermal stress is calculated from the average of thermal expansion coefficient of titanium alloy and diamond, $\alpha(\mathrm{T})$. The thermal stress $\sigma_{\text {th }}$ was calculate using the following relation ${ }^{24}$ :

$$
\sigma_{t h}=\int_{T_{g}}^{T_{a n b}} E /(1-v)\left[\alpha_{\text {diamond }}(T)-\alpha_{T i}(T)\right] d T
$$

where $\alpha(\mathrm{T})$ is the temperature dependence of the thermal expansion coefficient of titanium alloy and diamond and $E$ and $v$ are the Young's modulus and Poisson's ratio of the diamond film, respectively. Using $1345 \mathrm{GPa}$ for the value of the biaxial Young's modulus, E/(1-v) ${ }^{25}$, a constant and

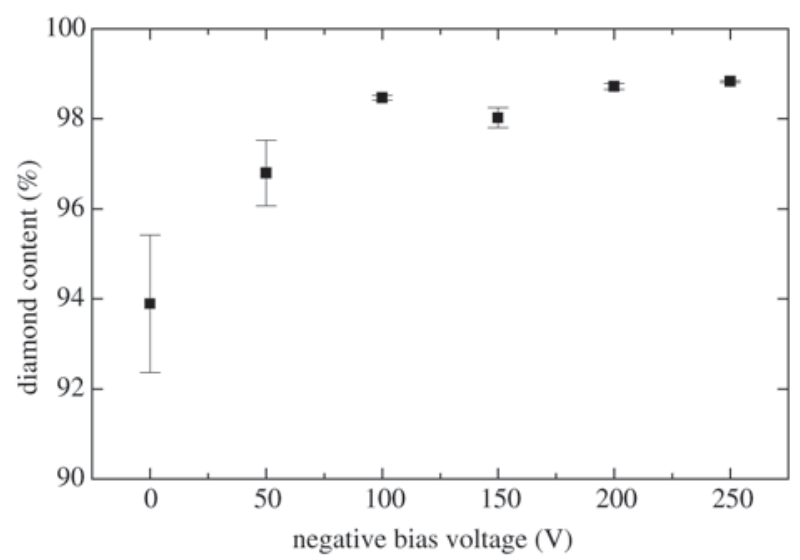

Figure 5. Amount of diamond relative to graphite as function of bias voltage. 
compressive thermal stress, $\sigma_{\text {th }}=-6.12 \mathrm{GPa}$, was found for a $1000 \mathrm{~K}$ deposition temperature.

The total residual stress was determined from the diamond Raman scattering line shifts. Calculation of the Raman shift as a function of the diamond structure parameter lead to a linear shift of $2.9 \mathrm{~cm}^{-1} / \mathrm{GPa}^{26-28}$. This value leads to the relation:

$$
\sigma \cong-\frac{\Delta v}{2.9} G P a
$$

where $\Delta \mathrm{n}$ is the shift of the Raman scattering peak of diamond films relative to natural diamond peak at $1332 \mathrm{~cm}^{-1}$. A positive (or negative) $\Delta \mathrm{n}$ corresponds to a compressive (or tensile) stress. In Fig. 6 is shown the residual stress as a function of applied negative bias. The error bar is the mean square deviation obtained from the five measurements in different places of the sample. We can observe that the residual stress is compressive and varied from -1.52 to $-1.48 \mathrm{GPa}$ between 0 and $-200 \mathrm{~V}$ applied bias, respectively, and above the $-200 \mathrm{~V}$, the compressive residual stress increased drastically to $-1.80 \mathrm{GPa}$. These results are in agreement with observed in Fig. 3. The grain coalescence is more apparent after $-200 \mathrm{~V}$ applied bias, so one can speculated that the thermal stress becomes dominant. This variation is associated with different stress components contributions for different stages of the film formation. Coherency strains due the lattice mismatch of film and substrate represent a well-know issue in heteroepitaxy. In principle, these strains can relax by the misfit dislocations at the interface, in this case, formed by the titanium carbide. With increasing particle size, the lattice expands and the lattice parameter approaches that of the bulk material. Adhesive constrains exerted by the substrate partially prevent the lattice from ex-

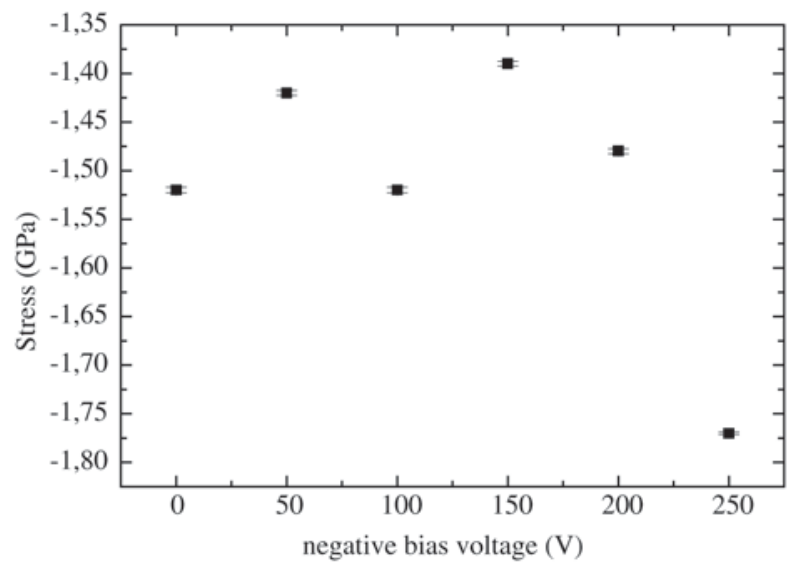

Figure 6. Total residual stress as function of bias voltage. panding, thus retaining compressive particle stress. If strain relaxation remains incomplete, however, coherency strains are expected to show up as coherency film stresses. Summarizing the influence of microstructure, the surface energy effect diminishes when individual grains coalesce, whereas strong compressive stresses are picked up due to disclination formation. Coherency strains would be superimposed onto these effects and would manifest themselves most clearly in continuous layers, for similar reasons to thermal stresses. The present analysis also shows that the total residual stress in diamond films can only be explained if other sources of internal stress generation can be identified, such as, the formation of the TiC interface and deposition temperature.

\section{Conclusion}

A BEN was performed with success in a Surfatron system. The diamond nucleation was strongly affected by the BEN parameters. At $-250 \mathrm{~V}$ bias condition, the grain density was approximately $1.6 \times 10^{9} \mathrm{~cm}^{-2}$, the average grain size was around of $200 \mathrm{~nm}$ and the diamond content in the film was approximately $98 \%$. This confirms that the high values of bias are recommended to get high diamond nucleation rate of diamond films with high quality.

The Raman spectra of all samples exhibited the stressed diamond peak around $1336 \mathrm{~cm}^{-1}$. Besides, another Raman peak at $1134 \mathrm{~cm}^{-1}$ indicates the presence of nanocrystalites inside the diamond thin film structure. These results suggest that the use of BEN in Surfatron system is a promising area of study in order to get diamond films with high adherence and smaller stress. Besides, this technique may be used to obtain smaller and highly oriented diamond (HOD) grains.

\section{Acknowledgements}

The authors are very grateful to FAPESP and CNPq for financial support, to Mr. Jognes Panasiewicz Junior and Mrs. Maria Lúcia B. de Mattos (Instituto Nacional de Pesquisas Espaciais) for SEM analyses.

\section{References}

1. Fedosseev, D.F.; Deryagin, B.V.; Varshankaya, I.G.; Laurentev, A.V Sov. Phys. JETP, v. 53, n. 1, p. 210, 1981.

2. Matsumoto S.; Sato, Y.; Tsutsumi, M.; Setaka, N.; J. of Mat. Science, v. 17, p. 3106, 1982.

3. Angus, J.C.; Hayman, C.C. Science, v. 241, p. 913, 1988.

4. Liou, Y.; Inspektor, A.; Weimer, R.; Messier, R. Appl. Phys. Lett., v. 55, n. 7, p. 31, 1989.

5. Ravi, K.V.; Koch, C.A.; Hu, H.S.; Joshi, A. J. of Mater. Res., v. 5, p. 2356, 1990.

6. Yarbrough, W.A.; Messier, R. Science, v. 247, p. 688, 1990.

7. Yugo, S.; Izumi, A.; Kanai, T.; Muto, T.; Kimura, T. Appl. 
Phys. Lett., v. 58, p. 1036, 1991.

8. Yugo, S.; Kanai, T.; Kimura, T. Diamond and Related Mater., v. 1, p. 388, 1992.

9. Michler, J.; Mermoux, M.; Kaenel, Y.; Haouni, A.; Lucazeau, G.; Blank, E. Thin Solid Films, v. 357, p. 189201, 1999.

10. Yugo, S.; Kanai, T.; Kimura, T. Diamond and Related Mater., v. 2, p. 328, 1993.

11. Yugo, S.; Semoto, K.; Hoshina, K.; Nakai, H.; Kimura, T. Diam. and Related Mater., v. 4, p. 903, 1995.

12. Moisan, M.; Zakrzewski, Z. J. Phys. D: Appl. Phys., v. 24, p. 1025-1048, 1991.

13. Moisan, M.; Zakrzewski, Z.; Pantel, R. J. Appl. Phys., v. 12, p. 219, 1979.

14. Zakrzewisk, Z.; Moisan, M.; Glaude, V.M.M.; Beaudry, C.; Leprince, P. Plasma Phys., v. 19, p. 77-83, 1977.

15. Moisan, M.; Zakrzewski, Z.; Pantel, R.; Leprince, P. IEEE Trans. On Plasma Sci., PS-12, 3, 1984.

16. Moisan, M.; Pelletier, J. "Microwave Excited Plasmas"Plasma Technology, v. 4, p. 5-140, 1992.

17. Yugo, S.; Semoto, K.; Nakamura, N.; Kimura, T.; Nakai, H.; Hashimoto, M. Diamond and Related Mater., v. 6, p .1047-1050, 1997.

18. Ma, Y.; Tsurumi, T.; Shinoda, N.; Fukunaga, O. Diamond and Related Mater., v. 4, p. 1325 - 1330, 1995.

19. Chiang, M.J.; Hon, M.H. Thin Solid Films, v. 389, p. 68 - 74, 2001.

20. Fu, Y.; Yan, B.; Loh, N.L. Surface and coating Tech., v. 130, p. 173-185, 2000.

21. Mitura, S.; Mitura, A.; Niedzielski, P.; Couvrat, P. Chaos, Solitions \& Fractals, v. 10, p. 2165-2176, 1999.

22. Wang, W.L.; Polo, M.C.; Sanchez, G.; Cifre, J.; Esteve, J. J. Appl. Phys., v. 80, p. 1846, 1996.

23. Ferreira, N.G.; Abramof, E.; Leite, N.F.; Corat, E.J.; Trava-Airoldi, V.J. Journal of Applied Physics, in press.

24. Slack, G.A.; Bartram, S.F. J. Appl. Phys., v. 46, p. 89, 1975.

25. Windishchmann, H.; Grey, K.J. Diamond Related Mater, v. 4, p. 837, 1995.

26. Kaenel, Y.; Stiegler, J.; Mitchler, J.; Blank, E. J. Appl. Phys., v. 81, p. 1726, 1997.

27. Kim, J.G.; Yu, J. Scripta Materials, v. 39, p. 807, 1998.

28. Boppart, H.; Straaten, J.; Silvera, I.F. Phys. Rev. B., v. 32, p. $1423,1985$. 